\title{
Sistem Kendali Robot Pemotong Rumput Diperintah Suara Berbasis Android
}

\author{
Jhonson Efendi Hutagalung1, Dahriansah ${ }^{2}$ \\ Teknik Komputer, STMIK Royal Kisaran ${ }^{1}$ \\ Manajemen Informatika, STMIK Royal Kisaran ${ }^{2}$ \\ jhonefendi12@yahoo.co.id ${ }^{1}$,andrinasution86@yahoo.com ${ }^{2}$
}

\begin{abstract}
To manage land for farming both agriculture and plantations will certainly be carried out. In the process of cutting grass, we can cut the grass on the laha so that it can be planted. The process of cutting grass can be done in various ways both manually and automatically. To open new land faster, we cut grass with engine power. But the details and limitations of cutting machines are there. So it needs to be made a robot that works in an automatic way without any human assistance to do the cutting so that the work is done quickly and the wider range of cutting results is greater. The system will work using remote technology from a distance using Bluetooth. This system aims to connect communication between wheeled robots and smartphones through bluetooth communication media. From the results of the testing, the author succeeded in applying Bluetooth technology to wheeled robots by giving instructions such as forward, backward, turn right, turn left, and stop. This robot is used to cut grass with a large area so that it does not need to be done by many enough with two or three people alternately working on cutting grass in terms of clearing new land. But the system here is in miniature form so that it needs to be implemented separately into the real form that will be faced in terms of cutting grass. The robot is controlled with Android, to move the dc dinamo, and use a dinamo driver so that the robot can move according to the commands stored in the program. This research has been successful and will be developed towards a better one with a real tool with large capacity.
\end{abstract}

Keywords: Technology, Bluetooth, Android, Drivers, DC Dinamos.

\begin{abstract}
Abstrak-Untuk mengelola lahan dijadikan ladang sudah pasti akan dilakukan proses pemotongan rumput. Proses pemotongan rumput dapat dilakukan dengan berbagai cara baik cara manual maupun otomatis. Untuk membuka lahan baru lebih cepat maka dilakukan pemotongan rumput dengan tenaga mesin. Tetapi jangankauan dan batasan dari pemotongan mesin masih terbatas. Sehingga perlu dibuat robot yang bekerja secara otomatis tanpa ada bantuan manusia dalam melakukan pemotongan sehingga pekerjaan dapat dilakukan dengan cepat dan batasan luas hasil pemotongan lebih besar. Sistem akan bekerja dengan menggunakan teknologi pengerak dari jarak jauh menggunakan bluetooth. Sistem ini bertujuan untuk menghubungkan komunikasi antara robot beroda dengan smartphone melalui media komunikasi bluetooth. Dari hasil pengujian, penulis berhasil mengaplikasikan teknologi bluetooth pada robot beroda dengan memberikan instruksi seperti maju, mundur, belok kanan, belok kiri, dan berhenti. Robot ini digunakan untuk memotong rumput dengan lahan yang luas sehingga tidak perlu lagi dikerjakan oleh banyak cukup dengan dua atau tiga orang secara bergantian mengerjakan pemotongan rumput dalam hal pembukaan lahan baru. Tetapi sistem ini masih dalam bentuk miniatur sehingga perlu implemenatasi tersendiri ke dalam bentuk nyata yang akan dihadapi dalam hal pemotongan rumput. Robot dikendalikan dengan Android, untuk mengerakkan dinamo tersebut, serta menggunakan driver dinamo agar robot dapat bergerak sesuai dengan perintah yang tersimpan di dalam program.Penelitian ini telah berhasil dan nantinya akan dikembangkann kearah yang lebih baik dengan alatyang nyata dengan kapasitas besar.
\end{abstract}


Kata kunci: Teknologi, Bluetooth, Android, Driver, Dinamo.

\section{PENDAHULUAN}

Semakin meningkatnya kemajuan teknologi saat ini telah merubah perkembangan perangkat pembuatan robot, seperti kebanyakan penggunaan semua pekerjaan. Dengan kontrol mikrokontroler Arduino Uno dihubungkan dengan koneksi bluetooth dapat mengendalikan gerakan robot untuk melakukan pemotongan rumput dalam membuka lahan baru di daerah pedesaan sehingga, pekerjaan dapat dilakukan dengan cepat dan tidak mebutuhkan pekerja yang banyak.

Robot pada setiap posisi industri dan usaha sekarang ini sangat dibutuhkan. Khususnya ini di dalam hal persiapan untuk membuka lahan pertanian baru sehingga para petani tidak lagi mengalami kesulitan dalam membuka lahan yang baru di berbagai tempat. Sehingga usaha mereka di bidang pengembangan pangan dapat dibutuhi karena lahan pertanian yang begitu banyak dapat dibuka. Dengan kontrol mikrokontroler Arduino Uno dihubungkan dengan koneksi bluetooth dapat mengendalikan gerakan robot untuk memotong rumput dengan menyelusuri setiap sisi lahan untuk memotong rumput sehingga dapat diselesaikan dengan cepat. Robot ini nanti dapat di manfaatkan di daerah pedesaan di kabupaten Asahan tepatnya didaerah Hessa Air Genting.

\section{METODOLOGI PENELITIAN}

\subsection{Langkah-langkah Proses Penelitian}

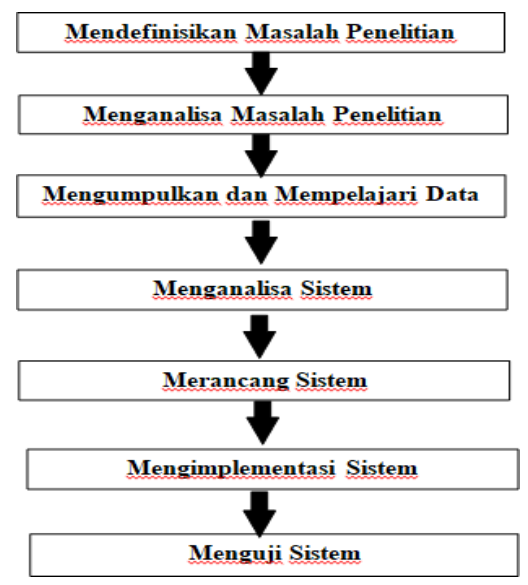

Gambar 1. Proses Penelitian

a. Mendefinisikan Masalah

Proses melakukan pendalaman dan menggali permasalahan yang ada untuk dapat dibuatkan sebuah sistem yang dapat berjalan sesuai dengan yang diharapkan.

b. Menganalisa Masalah Penelitian

Proses identifikasi masalah akan menimbulkan sebuah permasalahan yang kemudian akan dianalisa. Proses dalam menganalisa masalah penelitian adalah langkah untuk memahami sebuah masalah yang telah ditemukan dan 
ditentukan.

c. Mempelajari dan Mengumpulkan Data

Penelitian ini dilakukan agar menambah perbendaharaan kaidah, konsep, teoriteori yang mendukung dalam penyelesaian penelitian. Penelitian ini dilakukan melalui pemahaman dari buku-buku dan jurnal-jurnal yang ada kaitannya dengan penelitian yang sedang dilakukan.

d. Menganalisa Sistem

Studi ini dilakukan untuk menguatkan dasar-dasar pengerjaan penelitian ini sehingga tidak terlepas dari ketentua yang berlaku.

e. Merancang Sistem

Pembangunan pembuatan sistem meliputi perancangan sistem dengan bagian hardware dan software.

f. Mengimplementasi

Setelah layout PCB telah jadi maka lakukan pemasukan kaki komponen disesuaikan dengan rangkaiannya dan juga pasang kabel yang dibutuhkan untuk menghubungkan rangkaian ke catu daya ataupun ke bagian perangkat yang lain.

g. Menguji Sistem

Hardware dan Software yang dirancang selesai dibangun maka perlu dilakukan pengujian apakah bisa berjalan sesuai dengan yang direncanakan dan sesuai dengan tujuan dari penelitian.

\section{HASIL DAN PEMBAHASAN}

\subsection{Cara Kerja Sistem / Rangkaian}

Dibutuhkan suatu pengujian terhadap rancangan rangkaian yang telah dibuat. Sehingga dapat menghasilkan robot yang bekerja sesuai dengan perintah yang dberikan melalui smartphone. Sistem ini digunakan untuk menggerakkan dinamo yang bekerja berdasarkan control dari HP smartphone. Dimana pada smartphone telah dilakukan penyimpanan suara yang akan di deteksi oleh sensor suara yang telah terpasang pada smartphone android. Sensornya telah terhubung dengan aplikasi BT Voice Control For Arduino yang juga telah terpasang pada smartphone tersebut. Untuk menerima sinyal yang dikirim sensor adalah bluetooth. Bluetooth ini telah dihubungkan ke mikrokontroler Arduino. Sinyal yang diterima akan mengaktifkan Arduino sesuai dengan program yang telah disimpan. Arduino akan mengeluarkan tegangan ke driver sehingga driver akan menghubungkan arus ke dinamo akan bekerja atau berputar.

Berarti sistem ini membutuhkan smartphone sebagai aplikasi sensor, bluetooth HC-05, mikrokontroler Arduino sebagai pusat kontrol, driver dan dinamo sebagai beban listrik untuk di kontrol oleh sistem yang akan dibuat. 


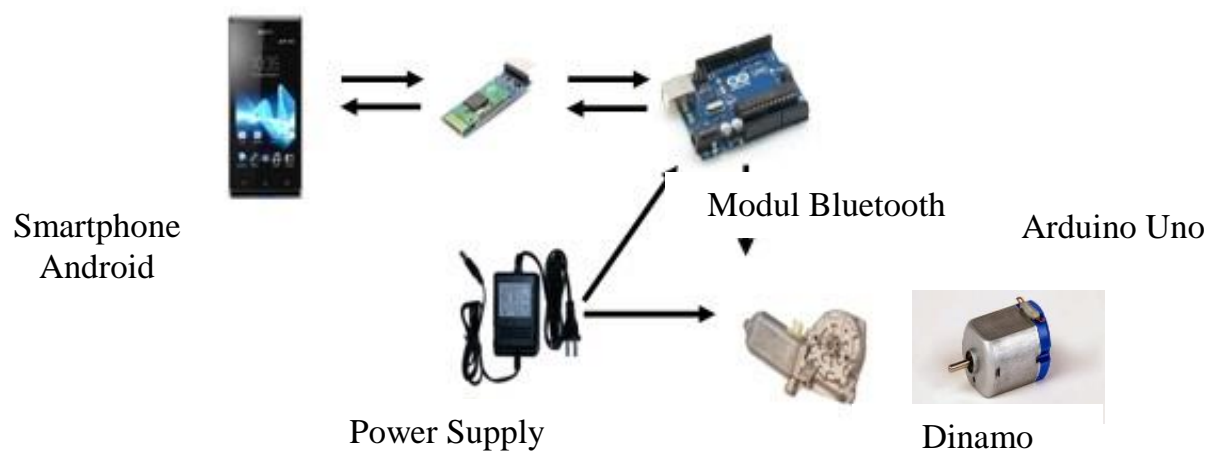

Gambar 2. Cara Kerja Sistem Pengontrolan Berbasis Android

\subsection{Desain Sistem}

\subsubsection{Desain Pada Smartphone Berbais Android}

Untuk desain smartphone yang difungsikan sebagai sensor untuk mengendalikan dinamo dapat dilakukan dengan memasang aplikasi BT voice Control for Arduino melalui Play Store. Setelah terpasang suara kita rekam dengan kata-kata yang berlaku untuk menghidupkan dan mematikan dinamo. Rekaman suara inilah nanti recognition oleh aplikasi sensor sehingga dapat menjadi sinyal yang dapat dideteksi.

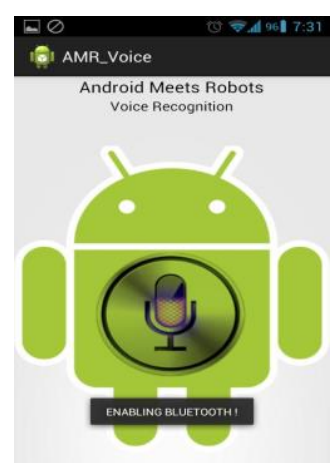

Gambar 3. Smartphone dengan BT Voice

\subsubsection{Desain Bluetooth HC-05}

Untuk desain Bluetooth HC-05 yang nantinya dikoneksikan dengan smartphone dengan menggunakan gelombang atau frekuensi 2,4 Ghz yang digunakan Bluetooth. Juga Bluetooth HC-05 ini dihubungkan juga ke Mikrokontroler Arduino menggunakan pin D11 terhubung ke Rx (receiver) dan D10 ke Tx (transmitter) serta juga terhubung ke VCC dan Ground masing-masing perangkat.

Juga Bluetooth Hc-05 ini dihubungkan ke Mikrokontroler Arduino menggunakan pin D11 terhubung ke Rx (receiver) dan D10 ke Tx (Transmitter) serta juga terhubung ke VCC dan Ground masing-masing perangkat, 


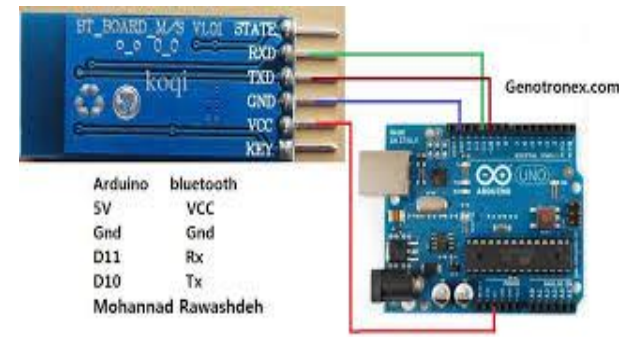

Gambar 4. Bluetooth HC-05 Terhubung ke Arduino

\subsubsection{Desain Rangkaian Driver Dinamo}

Rancangan untuk menyediakan driver yang dihubungkan dengan rangkaian untuk menggerakkan dinamo. Rancangan driver ini terdiri dari IC L293 D sebagai control untuk mengendalikan logika-logika yang masuk melalui bagian input, kemudian diproses oleh IC untuk menggerakkan dinamo pada dua sisi bagian output-nya, sehingga menghubungkan arus ke dua buah dinamo yang diberikan input-an dari mikrokontroler Arduino. Gambar rancangan desain letak driver dapat dilihat pada gambar di bawah ini :

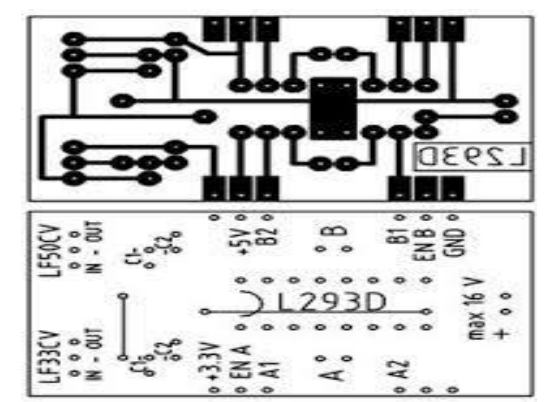

Gambar 5. Desain Layout Driver

\subsubsection{Desain Rangkaian Baterai}

Rancangan baterai untuk control robot dengan sensor suara ini menggunakan 4 buah baterai dengan tegangan 1,5 dihubungkan secara seri, sehingga akan diperoleh tegangan keseluruhan sebesar 6 Volt. Desainnya dapat dilihat pada gambar dibawah ini.

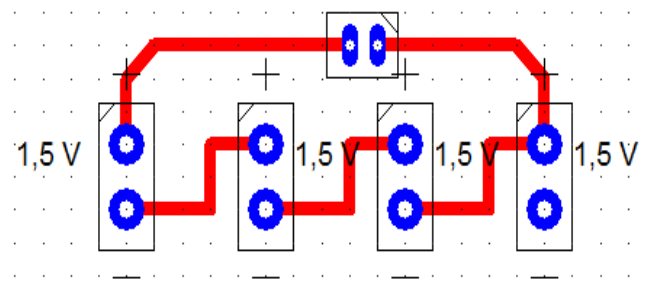

Gambar 6. Desain Rancangan Baterai

\subsection{Pengujian Sistem / Rangkaian}

Alat kontrol yang akan di bangun adalah untuk menghidupkan dua buah dinamo pada robot mobilan yang bergerak maju, mundur, belok kiri, belok kanan dan berhenti, sehingga alat ini dapat mempermudah kita dalam mengontrol robot 
dengan gerakan yang telah ditentukan pada program. Dalam pengendalian dinamo ini dilakukan menggunakan suara dengan kata-kata yang telah disimpan didalam IC mikrokontroler Arduino.

Untuk penerapan system maka diperlukan pengujian sistem. Sistem ini di buat dengan menggunakan smartphone berbasis Android, maka alat ini terdiri atas rangkaian mikrokontroler, sebagai pusat kontrol kendali dinamo, rangkaian Bluetooth HC-05, smartphone Android control, driver dan dinamo serta perangkat lunak atau program aplikasi boarduino voice of control. Untuk memastikan bahwa alat yang dirancang bekerja sesuai dengan diharapkan maka dilakukan pengujian perangkat keras dan juga perangkat lunak.

\subsubsection{Pengujian Software (Perangkat Lunak)}

Pengujian program ini dilakukan dengan cara pertama dimana, Mikrokontroler melakukan proses inisialisasi terlebih dahulu sesuai dengan jenis Mikrokontroler yang digunakan, untuk program ini khususnya menggunakan Mikrokontroler Arduino Uno. Setelah proses inisialisasi berhasil, selanjutnya adalah proses inisialisasi hubungan antara mikrokontroler dengan rangkaian sistem yang lainnya.

Dibutuhkan juga setting port dari sistem minimum yang dihubungkan ke laptop / komputer, dengan memilih Com 11 digunakan sebagai interface ke alatnya dan baud rate-nya 9600. Sistem bekerja pada saat penginputan suara dengan katakata tertentu pada smartphone Android voice control, mikrokontroler mendapatkan input dari pancaran frekuensi.

Perangkat lunak yang digunakan pada sistem kontrol pengendalian dinamo dengan menggunakan smartphone Android voice control adalah pemprograman Arduino Ide dengan bahasa C. setelah program dirancang selanjutnya program tersebut di upload ke mikrokontroler secara langsung melalui PC atau laptop untuk menyimpan program ke chip Arduino.

Untuk menguji program yang telah dirancang berhasil dan sesuai yang kita inginkan maka pada program sebelum di compile apakah terjadi kesalahan atau error. Kemudian sketch-nya di upload untuk disimpan ke chip Arduino. Setelah itu kita memberikan suara pada smartphone android vice control. Caranya mengucapkan kata-kata tertentu yang telah disimpan pada program.

Program diuji dilakukan dengan mengisikan program yang telah di rancang dengan menggunakan aplikasi arduino ide. Setelah diverifikasi apakah program sesuai atau tidak error maka program di download ke IC program arduino uno.

\subsubsection{Pengujian Hardware (Perangkat Keras)}

Robot ini dapat dihasilkan dihasilkan sesuai dengan yang diinginkan harus dicoba melalui pengujian-pengujian sehingga nanti dapat bekerja dengan baik.

a. Pengujian Catu Daya

Untuk pengujian catu daya dilakukan dengan menginputkan tegangan AC 220 volt kepada bagian primer trafo sehingga catu daya akan mengeluarkan tegangan sesuai dengan yang dibutuhkan.

Table 1. Pengujian Catu Daya

\begin{tabular}{|l|l|l|l|l|}
\hline No & Input & Hamba & Output & Ket \\
\hline
\end{tabular}




\begin{tabular}{|l|l|l|l|l|}
\hline & $\mathbf{( a c )}$ & $\begin{array}{l}\text { tan } \\
\text { (ohm) }\end{array}$ & $\mathbf{( d c )}$ & \\
\hline 1 & $220 \mathrm{~V}$ & $1 \mathrm{~K}$ & 12 & Stabil \\
\hline 2 & $220 \mathrm{~V}$ & $4 \mathrm{~K}$ & 12 & Stabil \\
\hline 3 & $220 \mathrm{~V}$ & $30 \mathrm{~K}$ & 10.90 & $\begin{array}{l}\text { Tidak } \\
\text { Stabil }\end{array}$ \\
\hline
\end{tabular}

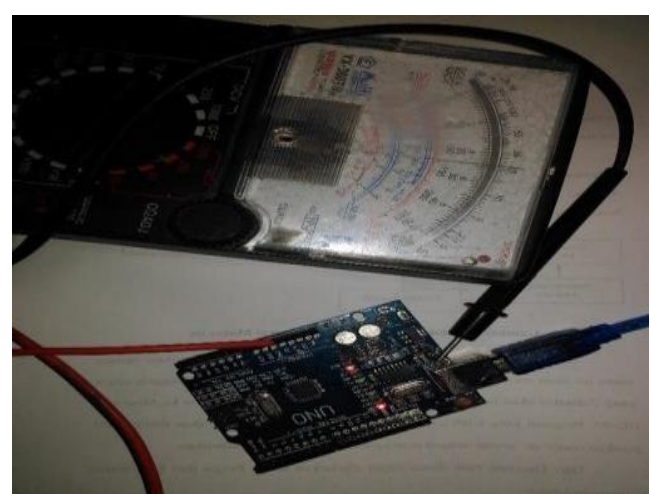

Gambar 7. Pengujian Catu Daya

Pengujian catu daya dapat dilakukan dengan mengikuti rangkaian pada gambar di bawah ini.

b. Pengujian Mikrokontroler

Pengujian dapat dilaksanakan dengan memberikan program kedalam IC mikrokontroler. Program yang digunakan adalah Bahasa C.

\subsection{Pengujian Rangkaian Driver terhubung ke Dinamo dc}

Untuk percobaan rangkaian driver dengan menekan tombol pada aplikasi android. Setelah kita penekanan maka kita ucapkan kata perintah yang telah disimpan. Perintah maju maka driver bekerja sehingga kedua dinamo berputar kearah kanan. Kemudian kalau kita ucapakan mundur maka kedua dinamo akan berputar kearah kiri. Rangkaian dapat di lihat pada gambar 3 di bawah ini :

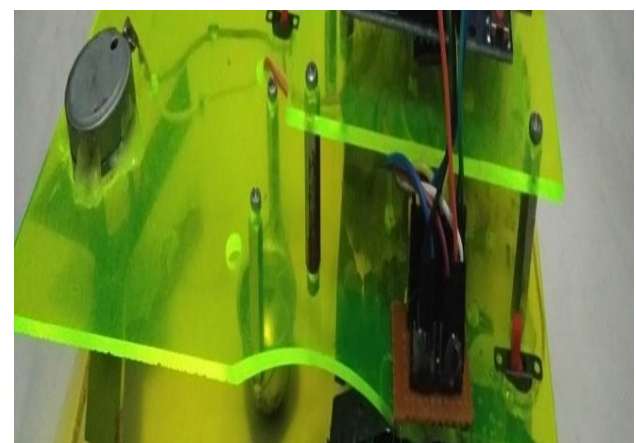

Gambar 8. Pengujian Rangkaian Driver ke Dinamo

Tabel 2. Pengujian Arus Pada Dinamo

\begin{tabular}{l|l|l|} 
Tegangan & Arus & Daya Dinamo|Hasil Dinamo
\end{tabular}




\begin{tabular}{|l|l|l|l|l|l|}
\hline NO & $\begin{array}{l}\text { Gerakan } \\
\text { Robot }\end{array}$ & $\begin{array}{l}\text { Dinamo DC } \\
\text { (Volt) }\end{array}$ & $\begin{array}{l}\text { Dinamo } \\
\text { (A) }\end{array}$ & (Watt) & \\
\hline 1 & Maju & $5 \mathrm{~V}$ & 0,7 & 3,5 & $\begin{array}{l}\text { Kedua Dinamo berputar ke } \\
\text { kanan }\end{array}$ \\
\hline 2 & Mundur & $5 \mathrm{~V}$ & 0,7 & 3,5 & Kedua Dinamo berputar ke kiri \\
\hline 3 & Belok kanan & $5 \mathrm{~V}$ & & & $\begin{array}{l}\text { Dinamo kiri stop, } \\
\text { Dinamo kanan }\end{array}$ \\
\hline 4 & Belok kiri & $5 \mathrm{~V}$ & 0,35 & 1,75 & $\begin{array}{l}\text { Dinamo kanan stop, Dinamo } \\
\text { kiri berputar ke kanan }\end{array}$ \\
\hline 5 & Berhen ti & $5 \mathrm{~V}$ & 0 & 0,35 & 1,75 \\
\hline
\end{tabular}

\section{Spesifikasi :}

Tegangan $=1-6 \mathrm{~V}$ DC Arus $=0,35-0,40 \mathrm{~A}$

Kecapatan Putaran=15000 - 17000 rpm Pengukuran arus dapat dihitung dengan:

$$
\mathbf{I}=\mathbf{P} / \mathbf{V}
$$

Dimana :

$\mathrm{P}=$ Daya Dinamo (Watt)

$\mathrm{I}=$ Arus Dinamo DC (Ampere) $\mathrm{V}=$ Tegangan Listrik (Volt)

Contoh:

Diketahui : Dinamo daya 4,8 Watt

Voltase (Baterai) 6 Volt

Ditanya:Kuat Arus?

Penyeelesaian : $\mathrm{I}=\mathrm{P} / \mathrm{V}=4,8 / 6=0,8 \mathrm{~A}$

Pada daya dinamo 9,6 Watt

sehingga arus menjadi $=0,8 \times 2=1,6 \mathrm{~A}$

\subsection{Pengujian Jarak Kendali Robot Dengan Smartphone}

Sebagai penentuan agar diperoleh jarak antara robot dengan smartphone maka dapat dilakukan. dengan menghidupkan robot kemudian smartphone di bawa untuk menjauh dari robot sampai nanti diketemukan jarak yang nantinya tidak dapat mengendalikan robot tersebut

Tabel 3. Pengujian Jarak antara Smartphone dengan Robot

\begin{tabular}{|c|ll|l|}
\hline No & Jarak (m) & Hasil Robot \\
\hline 1 & 2 & Bergerak \\
\hline 2 & 4 & Bergerak \\
\hline 3 & 6 & Bergerak \\
\hline 4 & 8 & Bergerak \\
\hline 5 & \multicolumn{2}{|c|}{10} & Bergerak \\
\hline 6 & \multicolumn{2}{|c|}{$13 \mathrm{dst}$} & Tidak Bergerak \\
\hline
\end{tabular}

\subsection{Logika Program}


Dalam pengontrolan robot dengan suara berbasis Android dapat dilakukan dengan merekam suara yang akan dideteksi oleh aplikasi sensor tersebut. Dengan perkataan "Maju" atau "Mundur" kondisi setiap saat dua kondisi tersebut maka pada aplikasi sensor tersebut dapat membedakan frekuensi suara frekuensi yang dihasilkan. Misalnya sensor mendeteksi frekuensi kata "Maju" akan diterima oleh Bluetooth yang nanti output nya menghasilkan logika misalnya"1110" yang tertera pada display serial Arduino Ide. Dan kondisi logika yang berbeda bila frekuensi dari kata "Mundur" misalnya mempunyai logika"1011". Logika ini akan di-input-kan dalam program yang dibuat melalui aplikasi Arduino Ide. Bila Arduino memproses data tersebut maka akan melakukan gerakan maju dan mundur pada robot.

\subsection{Analisa Hasil}

Setelah dilakukan pengujian mulai dari pengujian catu daya sampai pengujian mikrokontroler serta output yang dihasilkan, maka robot sebagai miniatur daat bergerak maju, mundur, belok kiri dan belok kanan sesuai dengan perintah yang diucapkan dan diterima oleh smarpthone. Agar dapat menghasilkan kerja yang baik smarphone dihubungkan dengan bluetooth yang mengkoneksikan antara smartphone dengan mikrokontroler arduino. Dengan sumber tegangan yang telah diberikan dari catu daya yang mengeluarkan tegangan 12 Volt. Dan untuk dinamo pemutar dihubungkan dengan sumber tegangan tersendiri sehingga dapat bekerja dengan baik dan kuat untuk memotong rumput yang agak tebal. Karena pada dinamo tersebut telah disisipkan sebuah pisau yang tajam untuk memotong rumput tersebut. Gambar dibawah ini adalah prototipe alat sistem pengendalian robot pemotong rumput dengan perintah suara berbasis Android.

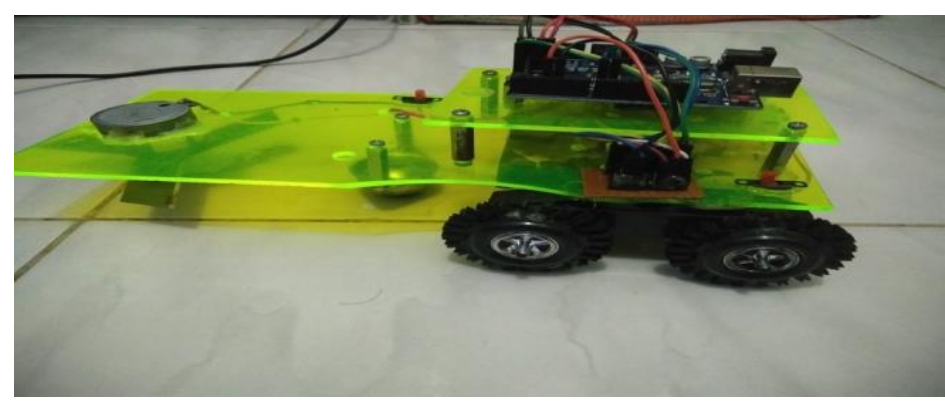

Gambar 9. Tampilan Alat Keseluruhan

\section{KESIMPULAN}

Dari pembahasan pada bab - bab sebelumnya dapat diambil kesimpulan, yaitu :

a. Kontrol Dinamo dilakukan dari jarak jauh dengan frekuensi yang dibutuhkan adalah frekuensi yaitu : 2,4 KHz pada sinyal ini dalam mengontrol dinamo bekerja dengan baik sejauh maksimal $10 \mathrm{~m}$,

b. Untuk mengaktifkan sebuah Dinamo harus diperhitungkan dari spesifikasi daya yang tertera pada dinamo tersebut sehingga nantinya alat yang dirancang bekerja sesuai dengan yang diinginkan dan dapat bergerak untuk melakukan pemotongan. 
c. Dalam hal dinamo untuk pemotong rumput harus menggunakan sumber tegangan tersendiri sehingga tidak mengganggu kelistrikan penggerakn rodanya.

d. Dalam mengimplentasikan robot ini menjadi penggunaan yang secara langsung harus menggunakan alat kontrol tambahan yaitu berupa relay dengan tegangan 24 volt sehingaa dapat menghubungkan peralatan dengan daya yang lebih besar.

\section{UCAPAN TERIMA KASIH}

Penulis memberikan penghargaan yang sebesar-besar kepada Yayasan Pendidikan Royal Teladan Asahan dan Kemenristekdikti yang telah memberi hibah penelitian skema Penelitian Dosen Pemula Tahun 2019 atas dukungan dana terhadap penelitian ini.

\section{DAFTAR PUSTAKA}

[1] Dr. M. Narayana. "Voice Control Robot using Android Aplication", International Journal of Enggineering Innovation \& Research, Vol. 4, Issue 2 ISSN: 2277- 5668, 2014

[2] Davis F. Sumajouw, "Perancangan Sistem Keamanan Rumah TInggal Terkendali Jarak Jauh",Ejournal Teknik Elektro dan Komputer, ISSN : 2301-8402, 2015.

[3] Devid Prastyawan, "Implementasi Model Robot Edukasi Menggunakan Mikrokontroler Atmega8 Untuk Robot Pemadam", Apijns- Indonesian Journal on Networking and Security ISSN: 2302- 5700, 2012.

[4] Fanny Andreas, dkk. "Rancang Bangun Sistem Kontrol dan Pemonitororan Lampu Rumah dengan Android". Jurnal Coding, Sistem Komputer Untan,2015.

[5] M. Dwisnanto Putra, " Robot Pintar Penyambut Costumer pada Pusat Perbelanjaan Kota Manado”. Jurnal Rekayasa Elektrika. Terakreditasi Ristekdikti No. 36b/E/KPT/2016. Volume 13 Nomor 1, 2017.

[6] Muhammad Ichwan, Pembangunan Prototipe Sistem Pengendalian Peralatan Listrik Pada Platform Android" Jurnal Informatika. No.1. Vol.4 Januari 2013. ISSN: 2087-5266, 2013.

[7] Indra Pati, "Robot Pengintai Menggunakan PC Berbasis Mikrokontoler 89S51", Universitas Guna Darma, Depok, 2012.

[8] Rafiuddin Syam, PhD, “Dasar-dasar Teknik Sensor”. Fakultas Teknik Univ.Hasanuddin, 2013. 